\title{
Is Public Sector Performance just a matter of money? The case of the Spanish regional governments
}

\author{
Raúl García-Gómez ${ }^{1}$ Jorge Onrubia ${ }^{1,2,3}$ • A. Jesús Sánchez-Fuentes ${ }^{1, *}$ \\ ${ }^{1}$ Instituto Complutense de Estudios Internacionales, Universidad Complutense de Madrid, Madrid, Spain \\ ${ }^{2}$ Fundación de Estudios de Economía Aplicada, Madrid, Spain \\ ${ }^{3}$ Governance and Economics Research Network, Universidade de Vigo, Ourense, Spain
}

Received: 31 December 2018

Revised: 11 June 2019

Accepted: 11 June 2019

\begin{abstract}
Efficient use of public resources is clearly a relevant issue to be studied from several points of view. Among others, it accounts for a significant share of the total economy activity and it deals with non-market oriented activities. In Spain, the regional level is particularly relevant due to the progressive decentralization of key public policies constituting the welfare state (as education, health, etc.) and their increasing financing needs, at the same time with important differences in fiscal capacity between them. Moreover, they mostly share (15 of 17) a common financing system in which an efficient use of resources is assumed but not evaluated. Our results show that normally a few of the regions tend to be the top performers, but there no regions performing poorly in every aspect. It is also worth noting that no dramatic changes can be seen in terms both of expenditure and performance during the recent Great Recession.
\end{abstract}

Keywords: public sector efficiency; public sector performance; Spanish Autonomous Communities

JEL Classification Codes: D24, D60, D61, H40, H50

\section{Introduction}

Efficient use of public resources is clearly a relevant issue to be studied from several points of view. On the one hand, public sector constitutes a significant proportion of the total economy activity (relatively more important for developed countries in which welfare state has a very long tradition). On the other hand, public sector typically deals with non-market oriented activities and, therefore, a standard cost-benefit or cost-effectiveness analysis seem less suitable

* Corresponding author. E-mail: ajsanchezfuentes@ucm.es.

Citation: García-Gómez, R., Onrubia, J., and Sánchez-Fuentes, A. J. (2019) Is Public Sector Performance just a matter of money? The case of the Spanish regional governments, Economics and Business Letters, 8(2), 74-84.

DOI: 10.17811/ebl.8.2.2019.74-84

Earlier versions of this note were presented at XXV Spanish Meeting on Public Economics (Valencia, Spain, January 25-26, 2018), the ICEI's Seminar of Research (March 1, 2018) and the XXI Applied Economics Meeting (Alcalá de Henares, Spain, June 7-8, 2018). 
to be carried out. The existence of different levels of government opens a relevant perspective to the problem of the efficiency of public spending, not too much addressed, in many cases due to the scarcity of good data (Adam et al., 2014).

In Spain, the regional level of government is particularly interesting due to the several reasons, among which the following stand out. First, the strong decentralization of key public policies (as education, health, etc.) jointly with their increasing financing needs led regional governments to have a growing relevance in determining whether public spending has been finally allocated efficiently. Second, the important differences in fiscal capacity existing between regions (Autonomous Communities, hereinafter ACs) encourage that the discussions about territorial equalization are permanently ongoing. Since the beginning of political decentralization in the early eighties, the Spanish equalisation system is based on expenditure needs of regions, which are essentially determined by the cost of the public services prior to their transfer, adjusted by demographic and territorial variables. Finally, ACs mostly share (15 of 17) a common financing system in which an efficient use of resources is assumed but not evaluated ${ }^{1}$.

Upon the basis of the methods developed in the field of productive efficiency (see Emrouznejad (2003), Kocher et al. (2006) and De Jorge and Santín (2010) as illustrative examples), a recent but growing literature has already showed some findings. However, the existing analyses applied specifically to the Public Sector Efficiency (PSE) mostly are country specific and focus either on a set of specific activities of the public sector (education, health, etc.) or on a specific government level (central, regional, municipalities, etc.). At regional level, Afonso and Scaglioni (2007), Hauner (2008), Hemmings (2006) and Mohanty and Bhanumurthy (2018) analyse the specific cases of Italy, Russia, Czech Republic and India, respectively.

This paper builds from the methodology presented by Afonso et al. (2005) where a FreeDisposable Hull (FDH) Analysis is used for carrying out a cross-country comparison of PSE and Performance (PSP). ${ }^{2}$ Their work made an influential turn on how to compare and study public efficiency as we will further see. Since then, several authors have used this approach for their own research, mainly at national and at municipal levels. As far as we are aware, regional level hasn't been tackled that much as in our analysis. The main novelty in our analysis is that we focus on Spanish regions following a State division which, although quite decentralised when compared to other countries, does not give the whole control to them. Specifically, our analysis focuses on public spending on education and health. Both public policies, transferred in their entirety to the ACs, constitute, as is known, two of the fundamental pillars of the modern welfare states.

Our results show that normally a few of the regions tend to be the top performers, while there isn't any region which performs poorly in every aspect. It is also worth noting that, although this time lapse takes a snapshot of the recession in Spain, no dramatic changes can be seen, as expenditure generally grew, and performance slightly decreased.

The rest of the article is organized as follows. In the second section, we present the data used in our study. The third section contains the methodological framework for our empirical analysis. In the fourth section, we present the main results achieved. Finally, the last section concludes and provides suggestions for further research.

\footnotetext{
${ }^{1}$ Basque Country and Navarre have their own financing system, with full fiscal capacity, the so-called "Foral regime".

${ }^{2}$ Non-parametric analysis have also been used on Spain, but most of the studies have focused on the provincial level, calculating municipal efficiency (see Balaguer-Coll et al. (2006), Giménez and Prior (2007), among others).
} 
Table 1. List of inputs used.

\begin{tabular}{|c|c|c|}
\hline \multirow{4}{*}{ Healthcare } & Primary & $\begin{array}{l}\text { - Medical personnel assigned to primary healthcare (per } 1.000 \text { assigned } \\
\text { people) } \\
\text { - Nursing personnel assigned to primary healthcare (per } 1.000 \text { assigned } \\
\text { people) }\end{array}$ \\
\hline & Hospital & $\begin{array}{l}\text { - Beds on day hospitals } \\
\text { - Rate of infection on hospitals } \\
\text { - Average stay (days) }\end{array}$ \\
\hline & Specialized & $\begin{array}{l}\text { - Operative CT scanners } \\
\text { - Medical MRI's } \\
\text { - Operative Hemodynamic monitors }\end{array}$ \\
\hline & Other & $\begin{array}{l}\text { - General mortality rate } \\
\text { - Citizens' degree of satisfaction with how healthcare system works }\end{array}$ \\
\hline \multirow[t]{2}{*}{ Education } & $\begin{array}{l}\text { Non- } \\
\text { Tertiary }\end{array}$ & $\begin{array}{l}\text { - Students on public high secondary education } \\
\text { - Suitability rate ( } 10 \text { years old }) \\
\text { - Suitability rate }(15 \text { years old }) \\
\text { - Rate of population who complete high secondary education }\end{array}$ \\
\hline & Tertiary & $\begin{array}{l}\text { - Graduate students } \\
\text { - Population with higher education ( } 25 \text { - } 64 \text { years old })\end{array}$ \\
\hline
\end{tabular}

Source: Own elaboration.

\section{Data}

Data used in our study has been collected from three primary sources aiming to replicate how PSE is modelled. In this regard, it is essential to replicate as best as possible the main competences assumed by the Regional governments. In the Spanish case, they are Health and Education. Consequently, we use Health indicators obtained from Spain's Ministry of Healthcare and Social Services and Equality ${ }^{3}$. Data on Education has been extracted from Ministry of Education, Culture and Sports ${ }^{4}$. Population data used was found at Annual Spanish Census made by INE 5 .

Table 1 present a full list with all the indicators considered. We have used a total of 16 inputs for our research, 10 of them belonging to Healthcare sector and the other 6 to Education.

In terms of expenditure classification, we just follow the functional decomposition published by the Spanish Government to ensure a stable availability and comparability inter periods. Consequently, as can be seen in Figure 1, we have split them into 5 subdivisions: Primary Care, Hospital Care and Specialized Care for Health; while Education was divided into Non-Tertiary and Tertiary Education.

As initial results showed, population may bias our results as those with less population (and a lower absolute expenditure) would be seen as most efficient. For this reason, all our absolute indicators have been expressed in relative figures (normalized by each region's population).

We have collected data from 2005 to 2015, when main policies were already in charge of regional government. Furthermore, we have merged $^{6}$ the results into three sub periods: 20052008, which reflects the Spanish performance prior to the Great Recession; 2009-2011, when regions had to cut their expenditure to comply with the new deficit requirements, and 2012-

\footnotetext{
${ }^{3}$ https://www.msssi.gob.es/en/home.htm.

${ }^{4}$ https://www.mecd.gob.es/portada-mecd/en/.

${ }^{5} \mathrm{http}: / /$ www.ine.es/welcome.shtml

${ }^{6}$ We consider the average values of different annual figures.
} 
2015, when national government changed and the last years of the recession are noticed. At a glance, the results let us see a balanced performance of each region before and after the key period of this important period. Although some indicators' definitions changed throughout time, these variations are already taken into consideration and standardized by the official sources. ${ }^{7}$

\section{Methodological framework}

We follow Afonso et al. (2005) regarding their methodological principles but looking to Spanish ACs, for which we compile a set of indicators for the sample period we include in our analysis (see previous section for further details). In short, we assume that PSP (and PSE, consequently) can be measured by a certain set of economic and social indicators.

In order to compute efficiency indicators, we also need to consider public spending data on each category specified above. They had to be normalised across regions, with the average taking the value of one for each category specified above.

Next, we present a brief description of our empirical strategy.

\subsection{Public Sector Performance Indicators}

The first step is to compute the PSP index by aggregating the info collected from each indicator/block after normalising the actual figures. ${ }^{8}$ We adopt an agnostic approach and state the same relative importance/weight to them. Moreover, for the sake of robustness, we follow recommendations adopted recently from similar indexes like the Human Development Index and compute it using geometric mean, instead of the alternative additive approach (see Herrero et al., 2012, for further details). ${ }^{9}$

$$
P S P_{i}=\sqrt[n]{\prod_{j=1}^{n} P S P_{i j}}
$$

where $i$ and $j$ are the region and indicator/category identifier, respectively, and $n$ the number of categories.

Figure 1. Division of the Spanish Regional Public Sector Performance.

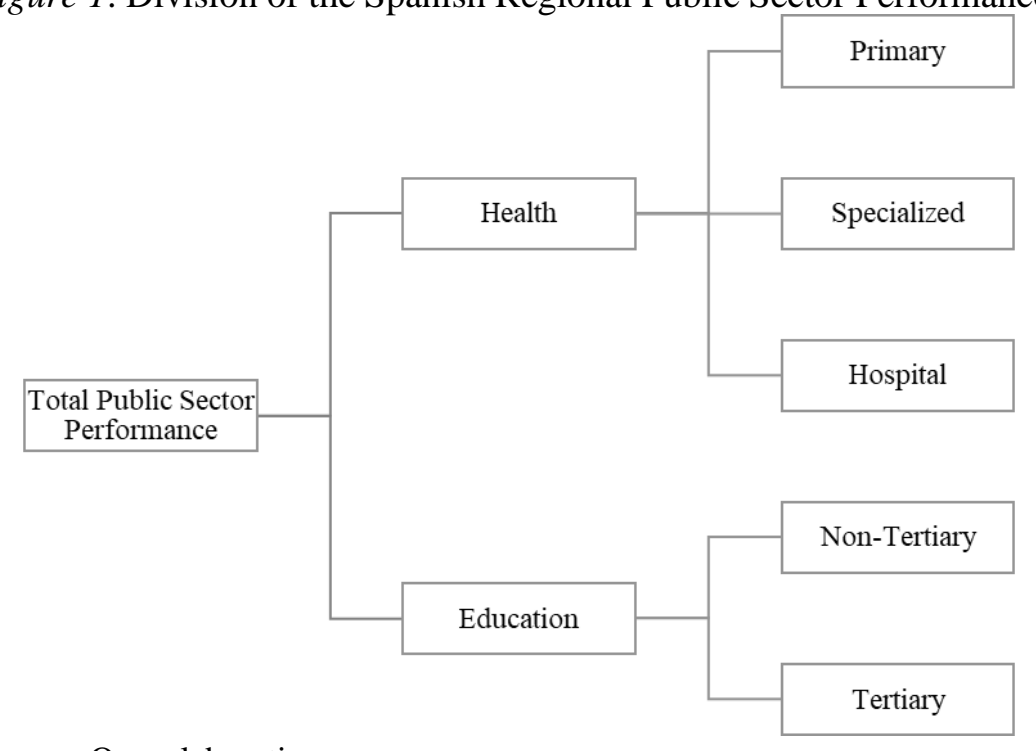

Source: Own elaboration.

\footnotetext{
${ }^{7}$ One aim of this paper is work with indicators published regularly (annually, in general terms) and used in the different forum (academic, institutional/political and social) to discuss about whether or not the regions budget allows them to face spending necessities.

${ }^{8}$ For the sake of clarity, all the output measures included are expressed in relative figures, to prevent from getting biased measures (in terms of size, for instance)

${ }^{9}$ Results considering the additive approach are available from authors upon request. The main conclusions remain.
} 


\subsection{Public Sector Expenditure Efficiency Analysis}

On the top of an output measure (PSP), we must account for the inputs used for obtaining it. As Afonso et al. (2005) stated, we restrict ourselves to consider suitable expenditure categories for measuring the efficiency with which a certain performance is achieved (Health and Education in our analysis).

In this regard, we consider a normalised measure of regional as the (per capita) public expenditure of each category (PEXN). There are alternative choices (as percentage of the regional Gross Domestic Product, for instance) but we think it reflects properly the opportunity costs of achieving the PSP estimated before. Having assumed this, we can compute the Public Sector Efficiency of category $j$ index as the following ratio;

$$
P S E_{j}=\frac{P S P_{j}}{P E X N_{j}}
$$

and grouping conveniently, we obtain the overall Public Sector Efficiency of region $i$ :

$$
P S E_{i}=\sqrt[n]{\prod_{j=1}^{n} P S E_{i j}}
$$

\subsection{Measuring Input and Output Efficiency via an FDH Analysis}

The information from previous subsections is finally used to compute the "wastefulness" of public spending across regions, i.e., the input and output efficiency of expenditure. For the sake of concreteness, we conduct an FDH efficiency analysis of public expenditure to our sample of 17 Spanish ACs.

Assume four regions, A, B, C, D and E that use a certain amount of public expenditures, measured on the horizontal axis in monetary units. They are then assumed to achieve a certain level of public spending performance, measured on the vertical axis. So, their efficiency is obviously different ( $\mathrm{E}$ is relatively inefficient in comparison with others). For instance, region $\mathrm{E}$ uses more input than region $\mathrm{A}$, but produces less output. On the other hand, being placed on the "production possibility frontier" means that there are no other regions besides them that deliver the same level of output with a lower level of input (A, B, C and D). Moreover, the distance may be different depending on the reference used. For E, there may be difference in considering the distance to $\mathrm{C}$-how much we are not producing due to inefficiencies, Output Oriented- or B -how much input we are using in excess, Input Oriented-).

Figure 2. Free Disposal Hull (FDH) frontier.

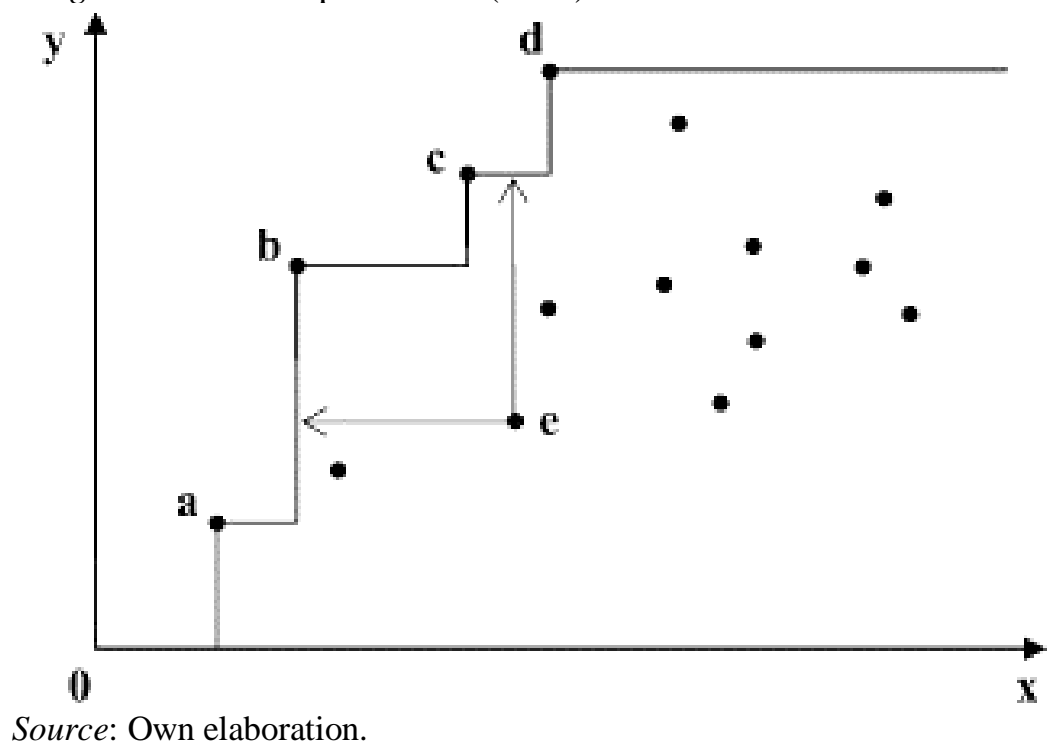


Figure 3. Per Capita Public Expenditure vs Population average annual growth (\%) over sample period (2005-2015), by sub periods.

2005-2015

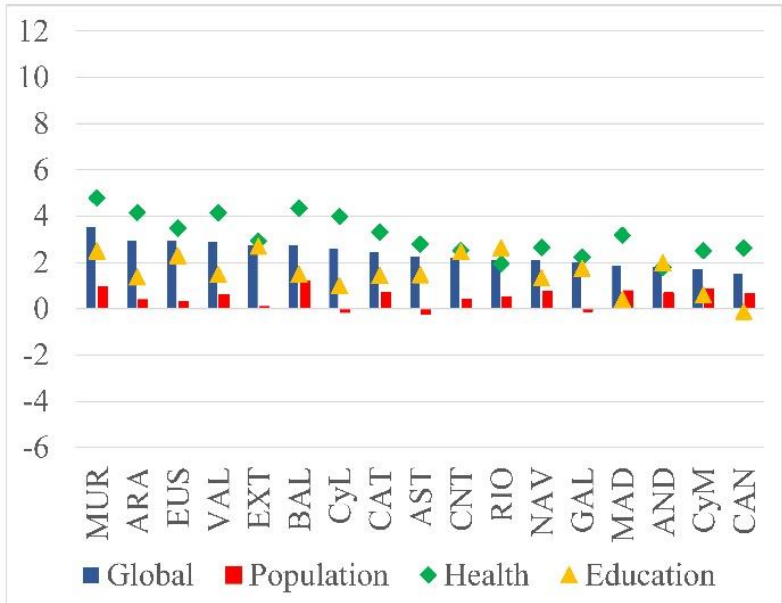

2009-2011

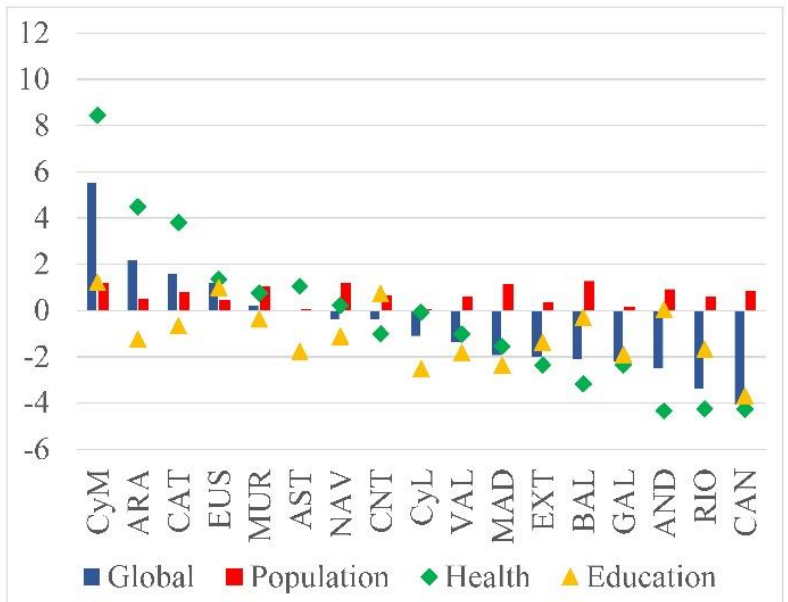

2005-2008

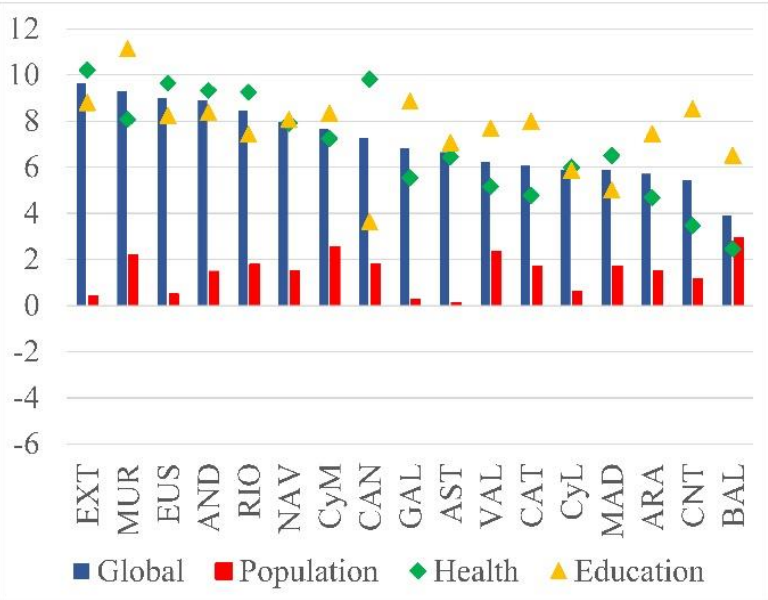

2012-2015

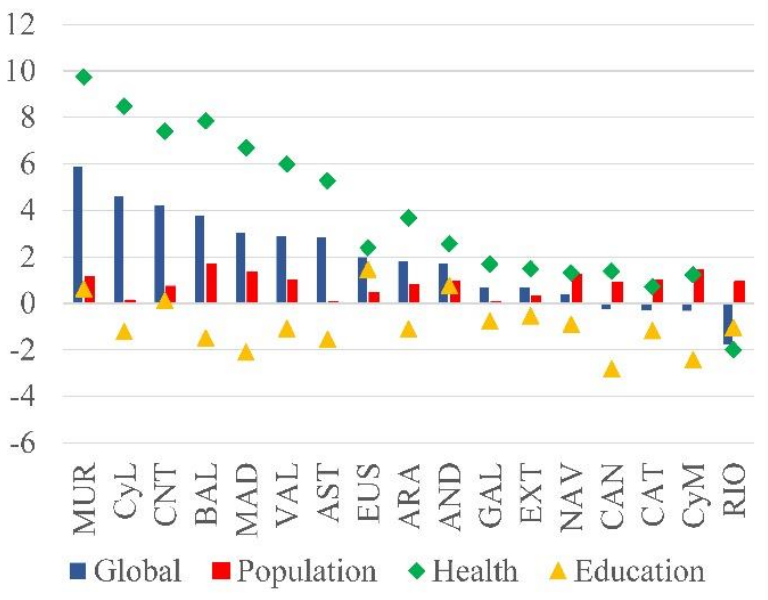

Notes: $(1)$ AND $=$ Andalucía, $\mathrm{ARA}=$ Aragón, AST $=$ Asturias $($ Principado de $), \mathrm{BAL}=$ Islas Baleares, $\mathrm{CAN}=$ Canarias, $\mathrm{CAT}=$ Cataluña, $\mathrm{CNT}=$ Cantabria, $\mathrm{CyL}=$ Castilla y León, $\mathrm{CyM}=$ Castilla La Mancha, $\mathrm{EUS}=$ Pais Vasco, $\mathrm{EXT}=$ Extremadura, GAL $=$ Galicia, $\mathrm{MAD}=$ Comunidad de Madrid, MUR = Murcia (Región de), NAV= Navarra (Comunidad Foral), RIO = La Rioja, VAL = Comunidad Valenciana. Source: Own elaboration.

\section{Results}

As stated before, our study analyses Spanish ACs' performances throughout the Great Recession in order to understand how essential public services provision (health and education) was affected by this unforeseen restrictive environment. There are still an open debate about the extent at which the measures adopted to rebalance the public finances have worsened the quality of public services provision or, on the contrary, have forced regional government to prioritize those good and services with a high social impact on the welfare of their citizens.

Analysing PSE means combine two different elements. On the one side, to follow the evolution of the amount of inputs available as it would allow policy makers either to implement new spending policies or increase the budget for the existing ones. On the other side, to measure the output achieved correspondingly.

Thus, we first briefly look to per capita public expenditure indicators referring to health, education and population. In addition, we compute the total amount resulting from the sum of Health and Education (what we call "global" hereinafter) in order to use it in later steps of our analysis. Figure 3 shows annual average per capita public expenditure growth rates for our full 
Figure 4(a). Spanish Regional Governments Normalised Public Sector Performance (PSP): Evolution over sample period (2005-2015).
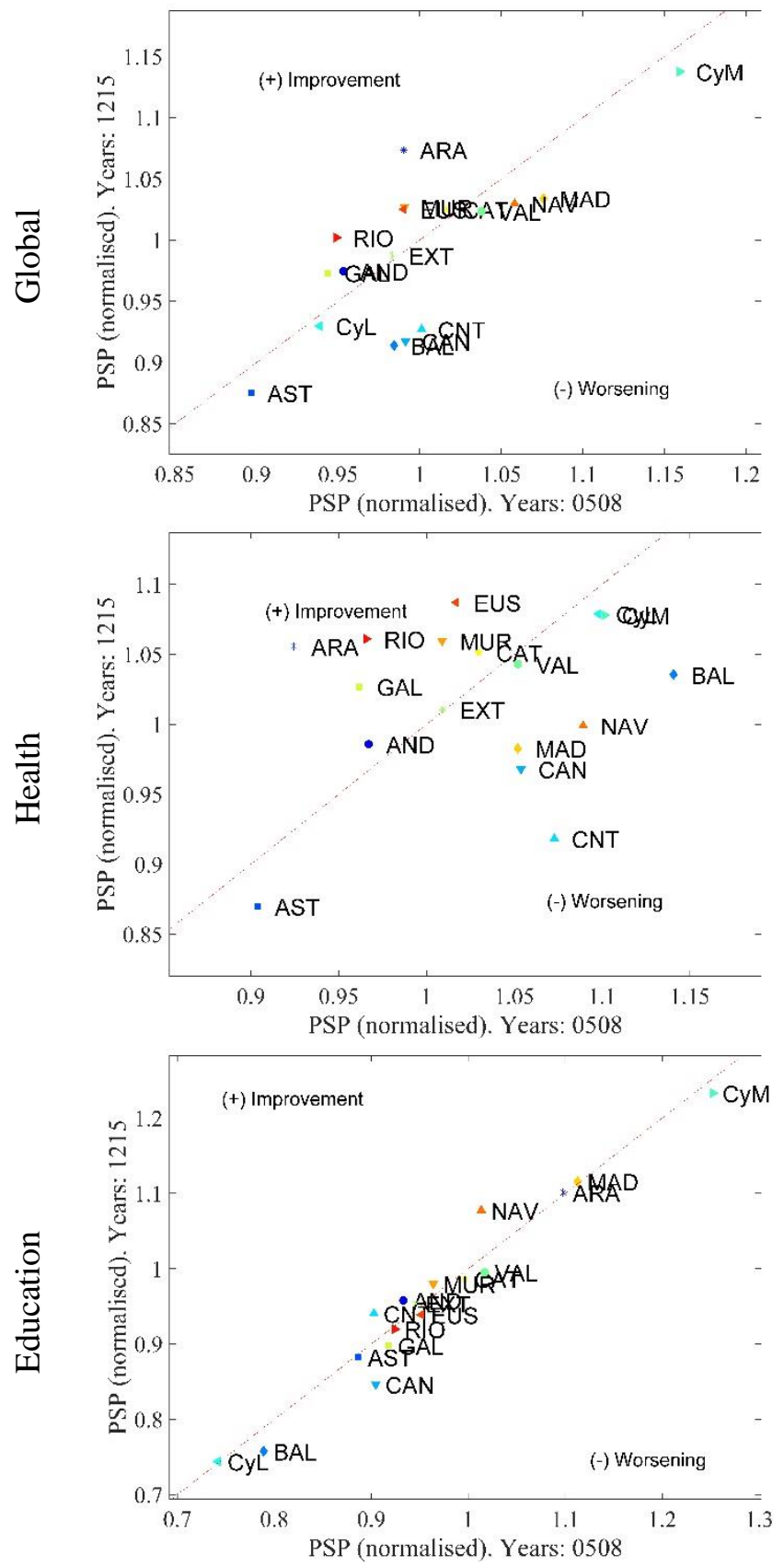

Source: Own elaboration.

sample and for three meaningful subperiods ${ }^{10}$. The first subperiod includes the latest years of the economic "boom" (2005 to 2008). It shows a expansionary spending policy in every region, with public expenditure rates that grew faster than their population. The second subperiod goes through the first stage of the Great Recession (2009-2011), when the average per capita variation of public expenditure became negative for most of the Spanish ACs. Only Castilla-La Mancha experienced an increase similar to the one observed during the previous period. For their part, Aragon, Catalonia, the Basque Country and Murcia registered modest growth rates (in all cases explained by the increase in Health), while none of them presented negative population variations. Finally, after the 2012 sovereign debt crisis, the recovery period until

\footnotetext{
${ }^{10}$ Regions have been sorted including first (to the left) those with higher "global" per capita growth rate.
} 
2015 showed positive rates of per capita variation in Health spending in all ACs (except La Rioja), while in Education they remained negative (except in Murcia, the Basque Country and Andalusia), with population average variations similar to those of the preceding subperiod.

As commented, we also think it is very worthy to analyse first the evolution of PSP in order to improve our understanding of PSE scores achieved later on subsequent stages. Figure 4 include a reference line (main diagonal) helping with their full understanding. First, triangle above (below) diagonal refer to those regions with an increase (decrease) in the measure throughout the period. In this case, an increase over the period will affect positively our PSE results (as we achieve a higher level of output). The decomposition between Health and Education help us to identify the latter (former) as the more stable (volatile) block during the whole period.

Figure 4(b). Spanish Regional Governments Normalised Public Sector Performance (PSP): Evolution over sample period (2005-2009 and 2009-2015).
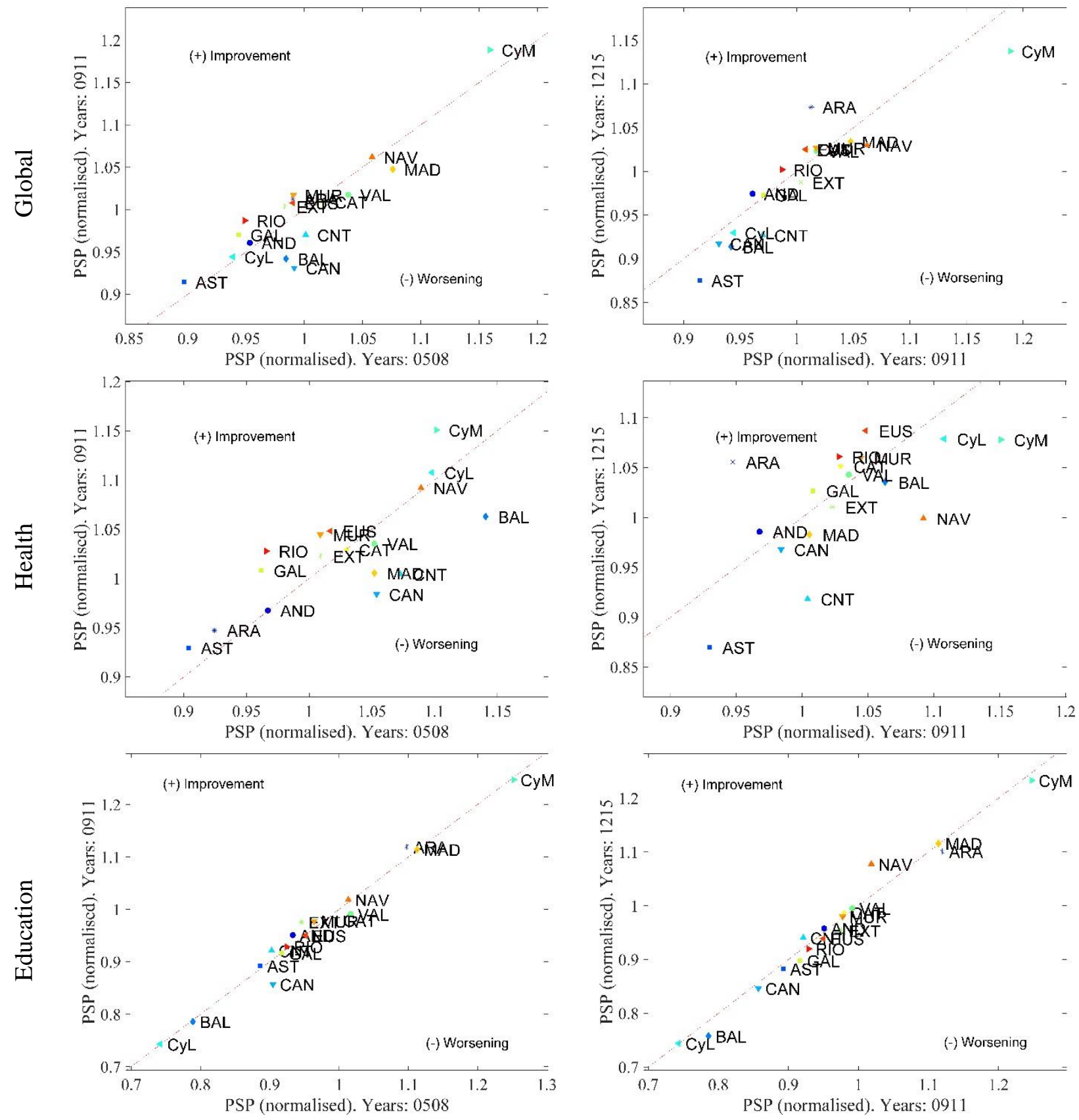

Source: Own elaboration. 
After our initial exploration of the main elements involved, we next describe our main results. In this regard, Figure 5 summarises for the main categories included in Figure 1 the main findings obtained. For the sake of concreteness, a short explanation follows. First column of panels include PSE scores for alternative time sub periods. Moreover, in the second column of panels, we show different perspectives of analysis (Input vs Output oriented) to obtain complementary view of the specific status/rank of each AC.

From this figure, some interesting conclusions emerge. First, there is no a clearly defined pattern/ranking respect to the Spanish ACs PSE. For the sake of illustration, ACs leading the Health index ranking (Andalucía y Castilla y León, among others) are not the best performers according to our education composite index. Moreover, analyst decisions regarding the perspective will introduce significant changes into the resulting ranking. Among others, País Vasco, Navarra and Aragón would be in better position when Output Oriented is considered whereas Andalucía, Cataluña, Canarias and Baleares would be in better position using Input Oriented.

Figure 5. Spanish Regions Public Sector Eciency (PSE) rankings: Main results.

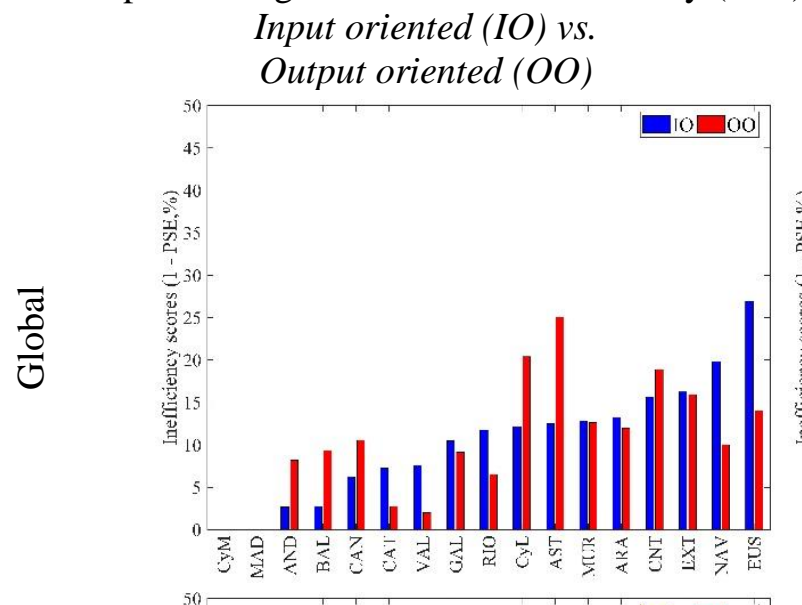

Full sample (05-15) vs. Subperiods (05-08 vs. 08-11 vs. 12-15)
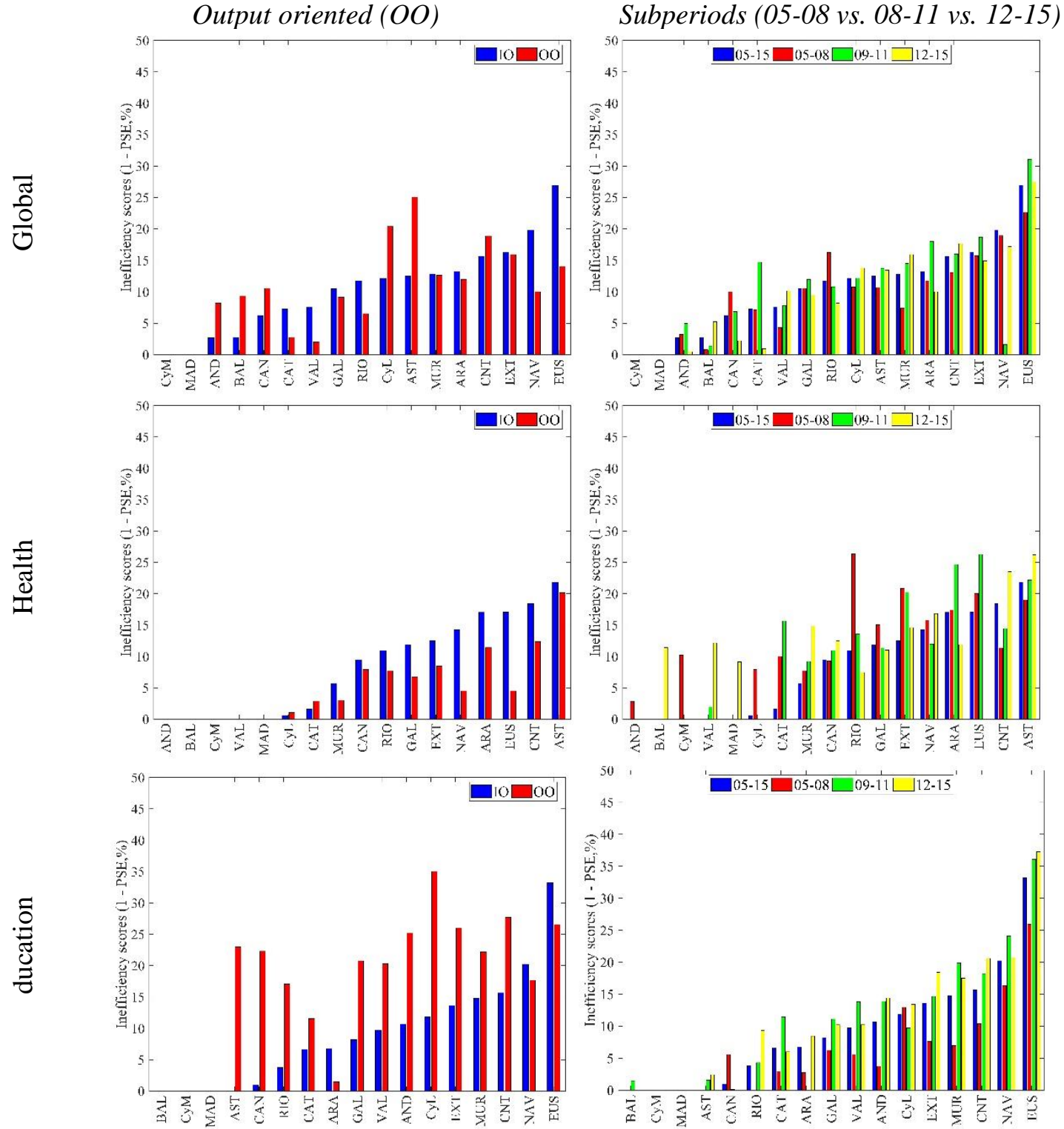

Notes: $(1) \mathrm{AND}=$ Andalucía, $\mathrm{ARA}=$ Aragón, $\mathrm{AST}=$ Asturias $($ Principado de), BAL $=$ Islas Baleares, $\mathrm{CAN}=$ Canarias, $\mathrm{CAT}=$ Cataluña, $\mathrm{CNT}=$ Cantabria, $\mathrm{CyL}=$ Castilla y León, $\mathrm{CyM}=$ Castilla La Mancha, $\mathrm{EUS}=$ Pais 
Vasco, $\mathrm{EXT}=$ Extremadura, GAL $=$ Galicia, MAD = Comunidad de Madrid, MUR = Murcia (Región de), NAV= Navarra (Comunidad Foral), RIO = La Rioja, V AL = Comunidad Valenciana. Source: Own elaboration.

Second, in terms of temporal evolution, there are some regions (Asturias and Cantabria, among others) with an increasing level of inefficiency during the time period analysed. On the contrary, regions leading the latest ranking "global" available (related to 2012-2015) were able to reduce or even compensate the existing difference at the beginning of our sample period (2005-2008).

Wrapping up the results, we see that normally a few of the regions tend to be the top performers, while there isn't any region which performs poorly in every aspect.

\section{Concluding remarks}

PSE improvements constitute a very promising way to overcome fiscal sustainability difficulties without worsening public goods provision. In this letter we analyse Spanish regional governments' performance over a very relevant recent period, the Great Recession. More importantly, we expand the policy-makers toolkit providing a methodology to monitor not only period-specific measures but also how they evolve over time. In this regard, we look both to our full sample period and to meaningful subperiods (2005-2008, 2009-2011, 2012-2015) to check for PSE sensitivity to the period considered.

Our empirical exercise has tentatively evaluated the role of the economic cycle in shaping the results obtained. First, we have compared average per capita variations in global expenditure, in its two components and in population for the three subperiods. Second, the changes observed reveal that implemented budgetary adjustments have asymmetrically affected ACs. On the one hand, those enjoying a higher per capita level of central government transfers before the Great Recession could better face the fiscal consolidation process, even improving their relative position in terms of efficiency. On the other hand, other communities were forced to reduce their performance, with a negative impact on their efficiency.

From a policy point of view, our results allows to extract very interesting conclusions and advance future contributions of this approach in identifying each AC' strengths and weaknesses. In addition, we think they help to consolidate good practices in every dimensions. Although merely illustrative, the results shown in this note allow us to emphasize the relevance of the systematic evaluation of regional public expenditure should have for ensuring a fair and efficient functioning of the ACs financing system. Without these spending reviews, it is impossible to disentangle to what extent the claims for additional funding from the CAs really corresponds to a lack of resources or simply are covering up inefficient management of their budgetary programs.

In the near future, we plan to reinforce this study in several ways. Firstly, by expanding the set of indicators used for each dimension. Second, our approach allows to carry out a systematic robustness analysis of the main results as we compute a whole distribution of models considering different indicators as dealer of each dimension. This helps to quantify how each performance indicator impact the PSE. Third, PSE changes over time might be decomposed by using Malquist indexes. They surely will contribute both to accurately isolate how business cycle impact regional PSE and to enrich policy discussion and information included in the decision-making process.

\section{Acknowledgements}

We gratefully acknowledge the useful comments and suggestions received from editors, A. Montes, E. Murillo and other participants in the abovementioned meetings and seminar. All the remaining mistakes are entirely our responsibility. R. García-Gómez thanks the hospitality and financing of the Complutense Institute of International Studies. J. Onrubia acknowledges the 
financial support of Spanish Ministry of Science, Innovation and Universities (before Ministry of Economy and Competitiveness), Project ECO2016-76506-C4-3-R. Sánchez-Fuentes acknowledges the financial support of the Regional Government of Andalusia (project SEJ 1512).

\section{References}

Adam, A., Delis, M. D., and Kammas, P. (2014) Fiscal decentralization and public sector efficiency: evidence from OECD countries, Economics of Governance, 15(1), 17-49.

Afonso, A., and Scaglioni, C. (2007) Efficiency in Italian regional public utilities' provision. In Marrelli, M., Padovano, F. and Rizzo I. (Eds): Servizi Publici: Nuove tendenze nella regolamentazione, nella produzione e nel finanziamento. Franco Angeli: Milano, Italy, 397418.

Afonso, A., Schuknecht, L., and Tanzi, V. (2005) Public sector efficiency: An international comparison, Public Choice, 123(3/4), 321-347.

Balaguer-Coll, M. T., Prior, D., and Tortosa-Ausina, E. (2007) On the determinants of local government performance: A two-stage nonparametric approach, European Economic Review, 51(2), 425-451.

De Jorge, J., and Santín, D. (2010) Los Determinantes de la eficiencia educativa en la Unión Europea, Hacienda Pública Española/Revista de Economía Pública, 193, 131-156.

Emrouznejad, A. (2003) An alternative DEA measure: A case of OECD countries, Applied Economics Letters, 10(12), 779-782.

Giménez, V. M., and Prior, D. (2007) Long-and short-term cost efficiency frontier evaluation: Evidence from Spanish local governments, Fiscal Studies, 28(1), 121-139.

Hauner, D. (2008) Explaining differences in public sector efficiency: Evidence from Russia's regions, World Development, 36(10), 1745-1765.

Hemmings, P. (2006) Improving public-spending efficiency in Czech regions and municipalities, OECD Economics Department Working Papers No. 499, OECD Publishing, Paris. doi: $10.1787 / 884741503537$

Herrero, C., Martínez, R., and Villar, A. (2012) A Newer Human Development Index, Journal of Human Development and Capabilities, 13 (2), 247-268.

Kocher, M. G., Luptacik, M., and Sutter, M. (2006) Measuring productivity of research in economics: A cross-country study using DEA, Socio-Economic Planning Sciences, 40(4), 314332.

Mohanty, R. K. and Bhanumurthy, N. R. (2018) Assessing public expenditure efficiency at Indian states, Working Paper, 225, National Institute of Public Finance and Policy New Delhi, New Delhi, available at http://nipfp.org.in/media/medialibrary/2018/03/WP_2018_225.pdf 